\title{
Efficacy and Safety of Ribavirin with Sofosbuvir Plus Ledipasvir in Patients with Genotype 1 Hepatitis C: A Meta-Analysis
}

\author{
Qiu-Feng He ${ }^{1} \cdot$ Qiong-Fang Zhang ${ }^{1} \cdot$ Da-Zhi Zhang ${ }^{1}$
}

Received: 14 April 2016/Accepted: 23 August 2016/Published online: 12 September 2016

(C) The Author(s) 2016. This article is published with open access at Springerlink.com

\begin{abstract}
Background Sofosbuvir and ledipasvir with or without ribavirin (RBV) regimens (SLR vs. SL) have exhibited promising results for the treatment of patients with hepatitis $\mathrm{C}$ virus (HCV) genotype 1 infection.

Aim To comprehensively compare the efficacy and safety of the SL and SLR regimen for the treatment of chronic $\mathrm{HCV}$ genotype 1 infections.

Methods The Cochrane Library, PubMed, Web of Science, and EMBASE databases were searched. Only RCTs that compared the efficacy and safety of SL or SLR regimen for the treatment of chronic HCV genotype 1 infection were included. The primary outcome measures were the sustained virological response weeks 12 (SVR12) post-treatment and adverse events (AEs).

Results Seven studies comprising 2601 patients were included. Compared with the SL regimen, SLR yielded a similar probability of having an SVR12 (RR 1.002, $95 \%$ CI $0.998,1.017, P=0.780$ ). Based on subgroup analyses, the addition of RBV to the 8-week SL regimen improved
\end{abstract}

Qiu-Feng He and Qiong-Fang Zhang have contributed equally to the article.

Da-Zhi Zhang

dzhzhang@yahoo.com

Qiu-Feng He

heqiufeng_1028@163.com

Qiong-Fang Zhang

scarehasgone@126.com

1 Key Laboratory of Molecular Biology for Infectious Diseases (Ministry of Education), Institute for Viral Hepatitis, Department of Infectious Diseases, The Second Affiliated Hospital, Chongqing Medical University, NO76 Lin Jiang Road, Yu Zhong District, Chongqing 400010, China the SVR12 rate. However, the SLR regimen for 12 or 24 weeks did not show a superior SVR12 rate regardless of treatment history and the presence or absence of cirrhosis. The pooled incidence of AEs was higher in patients that received the SLR treatment regimen (RR 1.140, $95 \% \mathrm{CI}$ $1.095,1.187, P=0.000$ ).

Conclusions The 12-week or 24-week SL regimen with a low incidence of AEs is as effective and well tolerated as the SLR regimen for the treatment of patients with chronic HCV genotype 1 infection.

Keywords Genotype 1 hepatitis C - Sofosbuvir . Ledipasvir · Ribavirin · Efficacy $\cdot$ Safety

\section{Introduction}

Recent epidemiological data from the World Health Organization (WHO) suggest that $\sim 130-150$ million people globally (2-3\% of the world's population) are infected with HCV. Individuals chronically infected with $\mathrm{HCV}$ are more likely to develop liver failure, liver cirrhosis, liver cancer, and other serious liver complications than uninfected individuals [1, 2]. $\mathrm{HCV}$ is responsible for $\sim 15-40 \%$ of the cases of cirrhosis and hepatic carcinoma worldwide and is also the leading indication for liver transplantation (LT) [3, 4]. Furthermore, HCV-related morbidity and mortality will continue to increase over the next few decades, even though the incidence of new HCV infections is declining [5, 6]. Unfortunately, there are currently no available vaccines for the prevention of $\mathrm{HCV}$ infections [7]. HCV infection remains a major global health problem, and early diagnosis and treatment are essential.

The standard of care (SOC) for the treatment of chronic hepatitis $\mathrm{C}$ consists of combination therapy with weekly 
PEG-interferon (PEG-IFN) and twice-daily oral RBV (PR) $[8,9]$; however, IFN-based treatments are accompanied by severe adverse effects, low tolerability, and a suboptimal sustained virological response (SVR, the most important target of a treatment for hepatitis $\mathrm{C}$ ). Therefore, interferonfree regimens are needed urgently [10, 11]. With the introduction of direct-acting antiviral agents (DAAs), the treatment of $\mathrm{HCV}$ infections is evolving rapidly, and interferon-free regimens are becoming a reality. DAAs are also associated with improved response rates and decreased treatment therapy durations. Several RCTs have shown that DAAs have higher SVR rates and fewer side effects than the PR regimen, particularly for HCV genotype 1 infections [12-15]. Genotype $1 \mathrm{HCV}$ is the most prevalent type of $\mathrm{HCV}$ worldwide (accounting for $\sim 50 \%$ of all $\mathrm{HCV}$ infections), and it is also the most difficult to cure [1, 16]. The American Association for the Study of Liver Diseases (AASLD) and the Infectious Diseases Society of America (IDSA) together updated guidelines for the treatment of HCV infection [17]. It was recommended that the treatment of HCV infections should consist of several DAAs (elbasvir/grazoprevir, LDV, SOF, simeprevir, daclatasvir, ombitasvir/paritaprevir/ritonavir, dasabuvir, velpatasvir), alone or in combination with RBV. Among the approved DAAs, the LDV/SOF combination therapy demonstrated excellent SVR rates in a series of related clinical trials [18-21]. However, it is unknown whether the addition of $\mathrm{RBV}$ to the LDV/SOF combination regimen improves the efficacy further. Furthermore, the potential AEs caused by the triple therapy are also unclear. Therefore, we performed a meta-analysis of RCTs to evaluate the efficacy and safety of SOF plus LDV with or without RBV in patients with genotype 1 hepatitis $\mathrm{C}$. This study provides significant guidance to clinicians when selecting treatment strategies for patients with genotype $1 \mathrm{HCV}$ infection.

\section{Methods}

\section{Literature Searches}

Two investigators (Qiu-feng $\mathrm{He}$ and Qiong-fang Zhang) performed electronic searches of the Cochrane Library, PubMed, Web of Science, and EMBASE databases independently between January 2015 and March 2016. The literature searches were performed using both medical subject heading (MeSH) terms and text words. The following keywords were used to identify relevant studies: "hepatitis C" or "HCV," "genotype," "ledipasvir," "sofosbuvir," and "ribavirin." Furthermore, the reference sections of all the articles identified were scanned, and any review articles on related topics were searched manually to identify additional potentially related studies. When necessary, we contacted authors of the studies to obtain further information.

\section{Inclusion and Exclusion Criteria}

Published or unpublished studies were included if they met the following criteria: (1) They studied patients with genotype $1 \mathrm{HCV}$ infections; (2) they compared the efficacy and safety of triple therapy (SLR) with dual therapy (SL); (3) the main outcome measure was the sustained virological response weeks 12 after the end of treatment (SVR12); (4) they reported the number of patients that achieved and failed to achieve SVR12 in each treatment group; and (5) they were RCTs. Studies were excluded if any one of the following occurred: (1) They included patients with nongenotype $1 \mathrm{HCV}$ infections; (2) they included patients infected with more than one type of hepatitis virus or other virus; (3) they failed to provide the main endpoint (SVR12); (4) they did not report the number of patients that achieved and failed to achieve SVR12 in each group; and (5) they were non-randomized controlled trials.

\section{Study Selection}

First, two reviewers (QFH and QFZ) screened the title and abstract of each article independently and identified publications potentially eligible for inclusion. After obtaining the full text of the studies identified in the initial screen, the same reviewers assessed the eligibility independently by reviewing the full text. Disputes between reviewers were resolved by consensus when possible. When required, a third investigator (DZZ) provided arbitration.

\section{Data Extraction}

Data from all selected articles were extracted by two investigators (QFH and QFZ) independently using a preestablished data extraction form. The following data were extracted: first author's name, year of publication, study design, country, number of patients, and the age, sex, race, body mass index (BMI), HCV RNA levels, drug dosage, and duration of treatment in each group. Any dispute between the investigators was resolved as described above.

\section{Quality Evaluation}

All the studies included in the meta-analysis were assessed for methodological quality using the Jadad score [22]. The new Jadad score contains four rating points: randomization (0-2 points), randomization concealment (0-2 points), blinding (0-2 points), and a reasonable explanation of the reasons for dropouts or withdrawals (0-1 point). Two points were given if the literature used appropriate 
methods, one point was added if the study failed to offer a detailed description of the methods, and no points were gained when neither of these occurred. The quality scale ranged from 0 (minimum) to 7 (maximum) points. A score of four or more indicated that a study contained highquality research.

\section{Outcomes}

Outcomes were defined prior to study initiation. To estimate the efficacy of SL treatment with or without RBV in the included studies, SVR12 was defined as the primary outcome. AEs were included as another main outcome to assess the safety of the two treatment regimens. The secondary outcomes were as follows: (1) virological relapse (post-treatment HCV RNA concentrations $>25 \mathrm{IU} / \mathrm{mL}$ at any time during follow-up after a serum HCV RNA $<25 \mathrm{IU} / \mathrm{mL}$ was recorded at the end of treatment); (2) treatment discontinuation due to the adverse events; and (3) five main AEs (nausea, headache, insomnia, fatigue, and anemia).

\section{Statistical Analyses}

The efficacy and safety outcomes investigated in this study were dichotomous variables; therefore, relative risk (RR) and $95 \%$ confidence intervals (CIs) were used to compare the safety and efficacy and safety of the two treatment regimens. Fixed-effects models were used by taking any differences in the treatment regimens among the included studies into account. $P$ values and $I^{2}$ indices were used to assess heterogeneity among the different studies; $P<0.05$ and $I^{2}>50 \%$ indicated significant heterogeneity. Funnel plots were used to identify the potential presence of publication bias, and Begg's or Egger's weighted regression statistics were used when necessary [23]. All analyses were conducted using Stata (version 12.0) software.

\section{Results}

\section{Search Results and Study Characteristics}

A total of 210 potentially relevant titles and abstracts were identified during the electronic database and manual searches. Of the 20 reports that were considered to be potentially relevant, seven met the study inclusion criteria. Thirteen potential trials were excluded for the following reasons: six included co-infected patients, five contained non-genotype $1 \mathrm{HCV}$ infection patients, and two failed to provide sufficient data on primary outcomes. Finally, seven RCTs involving genotype $1 \mathrm{HCV}$ infection patients were included in the meta-analysis (Fig. 1). The resulting

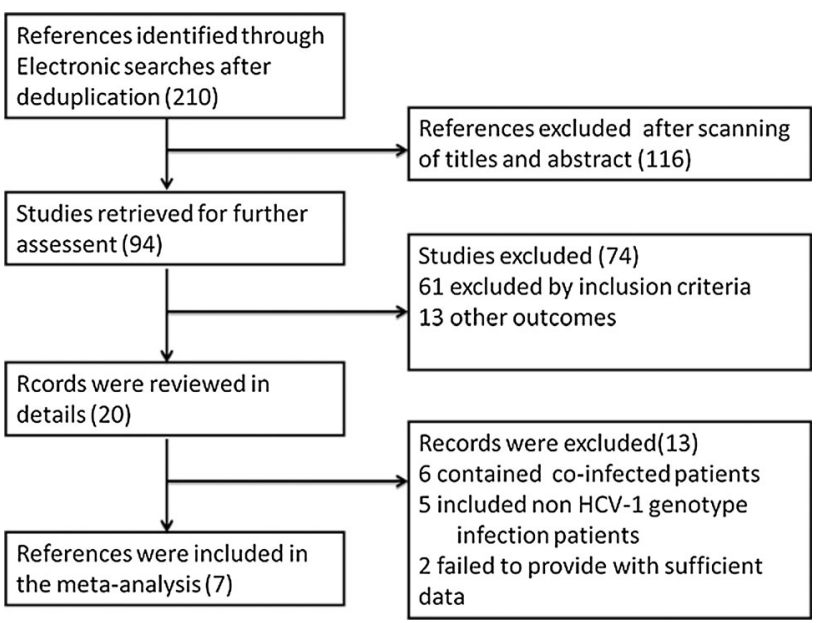

Fig. 1 Flowchart of the literature search and selection methods used

analyses included 2601 participants, of which 1204 were in the SLR therapy group. The full text of all eligible RCTs was published between 2014 and 2015. Patients in the included trials were from the USA, New Zealand, France, Japan, and other countries and were aged mainly 50-60 years. The basic characteristics of the seven RCTs included in the meta-analysis are presented in Table 1.

\section{Quality Assessment}

The methodological quality of the included trials was assessed using the Jadad scale, and the results are shown in Table 2. All the included studies had high methodological quality and scored five or more points. The randomization procedure was reported in sufficient detail to ensure that it was appropriate in four studies, but was not reported in three. In addition, all studies achieved a reasonable randomization concealment and blinded the treatment groups effectively. Finally, five of the seven articles reported the number and the reasons for any dropouts or treatment withdrawals.

\section{SVR12 in the SL and SLR Groups}

The meta-analysis of SVR12 in all patients receiving SLR and SL therapy is shown in Fig. 2. The SVR12 in genotype $1 \mathrm{HCV}$ infection patients ranged from 70 to $100 \%$. The pooled data showed that there was no statistically significant difference in the overall proportion of patients achieving SVR12 between the two groups $(\mathrm{RR}=1.002$, $95 \% \mathrm{CI}=0.988,1.017, P=0.780, I^{2}=5.3 \%$ ).

Based on treatment history, the presence or absence of cirrhosis and duration of treatment, we subsequently performed subgroup analyses. Treatment-naïve patients that received the SLR and SL regimens had a similar probability of achieving SVR12 $(\mathrm{RR}=0.994, \quad 95 \%$ 
Table 1 Main characteristics of the studies and patients enrolled in this meta-analysis

\begin{tabular}{|c|c|c|c|c|c|c|c|c|c|c|}
\hline Author & Year & \multicolumn{2}{|c|}{ Country } & $\begin{array}{l}\text { Study } \\
\text { design }\end{array}$ & $\begin{array}{l}\text { No. of } \\
\text { patients }\end{array}$ & Age (year) & $\begin{array}{l}\text { Male } \\
(\%)\end{array}$ & $\begin{array}{l}\text { White race } \\
(\%)\end{array}$ & BMI $\left(\mathrm{kg} / \mathrm{m}^{2}\right)$ & $\begin{array}{l}\text { HCV RNA } \\
(\log 10 \mathrm{IU} / \mathrm{ml})\end{array}$ \\
\hline $\begin{array}{l}\text { Eric et al. } \\
{[24]}\end{array}$ & 2014 & \multicolumn{2}{|c|}{ America } & RCT & $42 / 58$ & $\begin{array}{l}51.0 \pm 10.4 / \\
49.0 \pm 10.3\end{array}$ & $\begin{array}{l}56.5 / \\
70.0\end{array}$ & $95.2 / 87.9$ & $\begin{array}{l}30.7 \pm 6.4 / \\
29.4 \pm 6.0\end{array}$ & $\begin{array}{l}6.1 \pm 0.6 / \\
6.2 \pm 0.7\end{array}$ \\
\hline $\begin{array}{l}\text { Edward et al. } \\
\text { [25] }\end{array}$ & 2014 & \multicolumn{2}{|c|}{$\begin{array}{l}\text { New } \\
\text { Zealand }\end{array}$} & RCT & $43 / 10$ & $\begin{array}{r}49.0 \pm 10.6 / \\
61.0 \pm 4.9\end{array}$ & $\begin{array}{l}53.5 / \\
100.0\end{array}$ & $95.0 / 80.0$ & $\begin{array}{l}25.1 \pm 4.1 / \\
31.0 \pm 6.8\end{array}$ & $\begin{array}{l}6.2 \pm 0.9 / \\
6.5 \pm 0.6\end{array}$ \\
\hline $\begin{array}{c}\text { Kris et al. } \\
{[26]}\end{array}$ & 2014 & \multicolumn{2}{|c|}{ America } & RCT & $216 / 431$ & $\begin{array}{l}51.0 \pm 8.3 / \\
53.0 \pm 8.6\end{array}$ & $\begin{array}{l}54.2 / \\
62.5\end{array}$ & $81.5 / 62.9$ & $\begin{array}{c}28.0 \pm 6.3 / \\
28.0 \pm 4.2\end{array}$ & $\begin{array}{l}6.4 \pm 0.7 / \\
6.5 \pm 0.8\end{array}$ \\
\hline $\begin{array}{l}\text { Nezam et al. } \\
\text { [27] }\end{array}$ & 2014 & \multicolumn{2}{|c|}{ France } & RCT & $434 / 431$ & $\begin{array}{l}53.0 \pm 9.4 / \\
53.0 \pm 9.6\end{array}$ & $\begin{array}{l}56.9 / \\
61.7\end{array}$ & $85.5 / 84.5$ & $\begin{array}{l}27.0 \pm 4.6 / \\
27.0 \pm 4.5\end{array}$ & $\begin{array}{l}6.4 \pm 0.7 / \\
6.3 \pm 0.7\end{array}$ \\
\hline $\begin{array}{l}\text { Nezam et al. } \\
{[28]}\end{array}$ & 2014 & \multicolumn{2}{|c|}{ America } & RCT & $222 / 218$ & $\begin{array}{l}54.0 \pm 7.6 / \\
56.0 \pm 7.2\end{array}$ & $\begin{array}{r}62.6 / \\
67.9\end{array}$ & $82.4 / 80.3$ & $\begin{array}{c}28.0 \pm 4.3 / \\
28.0 \pm 4.2\end{array}$ & $\begin{array}{l}6.5 \pm 0.6 / \\
6.5 \pm 0.5\end{array}$ \\
\hline $\begin{array}{l}\text { Marc et al. } \\
\text { [29] }\end{array}$ & 2015 & \multicolumn{2}{|c|}{ France } & RCT & $77 / 78$ & $\begin{array}{l}56.0 \pm 7.4 / \\
57.0 \pm 10.7\end{array}$ & $\begin{array}{l}75.3 / \\
71.8\end{array}$ & $98.7 / 96.2$ & $\begin{array}{r}27.9 \pm 5.5 / \\
26.3 \pm 4.2\end{array}$ & $\begin{array}{l}6.5 \pm 0.5 / \\
6.5 \pm 0.6\end{array}$ \\
\hline $\begin{array}{l}\text { Masashi et al. } \\
\text { [30] }\end{array}$ & 2015 & \multicolumn{2}{|c|}{ Japan } & $\mathrm{RCT}$ & $170 / 171$ & $\begin{array}{l}59.0 \pm 9.5 / \\
60.0 \pm 9.2\end{array}$ & $\begin{array}{l}42.7 / \\
40.4\end{array}$ & NA & $\begin{array}{c}23.3 \pm 3.1 / \\
23.3 \pm 3.6\end{array}$ & $\begin{array}{l}6.6 \pm 0.5 / \\
6.6 \pm 0.5\end{array}$ \\
\hline Author & & Year & \multicolumn{2}{|l|}{ Country } & \multicolumn{4}{|c|}{ SLR drug dosage (mg/day) } & \multicolumn{2}{|c|}{$\begin{array}{l}\text { Duration of treatment } \\
\text { (weeks) }\end{array}$} \\
\hline Eric et al. [24] & & 2014 & \multicolumn{2}{|c|}{ America } & \multicolumn{4}{|c|}{$\begin{array}{l}\text { SOF + LDV + RBV1000 (weight }<75 \mathrm{~kg} \text { )/1200 mg } \\
\quad \text { (weight } \geq 75 \mathrm{~kg} \text { ) }\end{array}$} & \multicolumn{2}{|l|}{8} \\
\hline Edward et al. [25] & & 2014 & \multicolumn{2}{|c|}{$\begin{array}{l}\text { New } \\
\text { Zealand }\end{array}$} & \multicolumn{4}{|c|}{$\begin{array}{l}\text { SOF + LDV + RBV1000 (weight }<75 \mathrm{~kg} \text { )/1200 mg } \\
\quad \text { (weight } \geq 75 \mathrm{~kg} \text { ) }\end{array}$} & \multicolumn{2}{|l|}{12} \\
\hline Kris et al. [26] & 20 & \multicolumn{3}{|c|}{ America } & \multicolumn{4}{|c|}{$\begin{array}{l}\text { SOF + LDV + RBV1000 (weight }<75 \mathrm{~kg} \text { )/1200 mg } \\
\quad(\text { weight } \geq 75 \mathrm{~kg})\end{array}$} & \multicolumn{2}{|l|}{$8-12$} \\
\hline Nezam et al. [27] & 20 & \multicolumn{3}{|c|}{ France } & \multicolumn{4}{|c|}{$\begin{array}{l}\text { SOF + LDV + RBV1000 (weight }<75 \mathrm{~kg} \text { ) } / 1200 \mathrm{mg} \\
\quad \text { (weight } \geq 75 \mathrm{~kg} \text { ) }\end{array}$} & \multicolumn{2}{|l|}{$12-24$} \\
\hline Nezam et al. [28] & 20 & 14 & Americ & & $\begin{array}{l}\text { SOF }+ \text { LDV } \\
\quad(\text { weight } \geq 7\end{array}$ & $\begin{array}{l}\text { RBV1000 (weig } \\
\text { g) }\end{array}$ & $75 \mathrm{~kg}) / 1$ & $00 \mathrm{mg}$ & $12-24$ & \\
\hline Marc et al. [29] & 20 & 15 & France & & $\begin{array}{l}\text { SOF }+ \text { LDV } \\
\quad \text { (weight } \geq 7\end{array}$ & $\begin{array}{l}\text { RBV1000 (weig } \\
\text { g) }\end{array}$ & $75 \mathrm{~kg}) / 1$ & $00 \mathrm{mg}$ & $12-24$ & \\
\hline $\begin{array}{l}\text { Masashi et al. } \\
\text { [30] }\end{array}$ & 20 & 15 & Japan & & $\begin{array}{l}\mathrm{SOF}+\mathrm{LDV} \\
\mathrm{SOF}+\mathrm{LDV} \\
\mathrm{SOF}+\mathrm{LDV}\end{array}$ & $\begin{array}{l}\text { RBV600 (weigh } \\
\text { RBV800 (60 kg } \\
\text { RBV1000 (weig }\end{array}$ & $\begin{array}{l}60 \mathrm{~kg}) \\
\text { veight } \leq \\
80 \mathrm{~kg})\end{array}$ & $0 \mathrm{~kg})$ & 12 & \\
\hline
\end{tabular}

$\mathrm{SLR}=\mathrm{SOF}+\mathrm{LDV}+\mathrm{RBV} ; \mathrm{SL}=\mathrm{SOF}+\mathrm{LDV}$. Values denote patients in the SLR group (before slash) and those in the SL group (after slash). Values of age, BMI, and HCV RNA presented as means. The drug dosage for SOF, $400 \mathrm{mg} / \mathrm{day}$; and for LDV, $90 \mathrm{mg} / \mathrm{day}$ in SL and SLR regimen

$N A$ not available, $B M I$ body mass index

$\mathrm{CI}=0.975, \quad 1.014, \quad P=0.567, \quad I^{2}=0.0 \%$. Similar observations were made in previously treated patients $(\mathrm{RR}=1.020, \quad 95 \% \quad \mathrm{CI}=0.990, \quad 1.051, \quad P=0.201$, $I^{2}=32.6 \%$ ). As for the presence or absence of cirrhosis, the SLR regimen did not show a superior SVR12 rate in cirrhotic patients $(\mathrm{RR}=1.022,95 \% \mathrm{CI}=0.955,1.094$, $\left.P=0.528, \mathrm{I}^{2}=70.9 \%\right)$ or patients including those with cirrhosis $\quad(\mathrm{RR}=1.003, \quad 95 \% \quad \mathrm{CI}=0.990, \quad 1.016$, $\left.P=0.629, I^{2}=0.0 \%\right)$. Considering the duration of treatment, there was no statistically significant difference in the proportion SVR12 between the SLR and SL groups in patients receiving 12 weeks of treatment $(\mathrm{RR}=1.010$, $95 \% \mathrm{CI}=0.989,1.031, \quad P=0.374, I^{2}=59.0 \%$ ) or patients receiving 24 weeks of treatment $(\mathrm{RR}=1.010$, $95 \% \mathrm{CI}=0.988,1.025, P=0.496, I^{2}=44.6 \%$ ). Only
SVR12 rate among patients who received 8 weeks of SLR therapy was statistically superior to that among patients who received 8 weeks of SL therapy $(\mathrm{RR}=1.040,95 \%$ $\left.\mathrm{CI}=1.001,1.081, P=0.047, I^{2}=0.0 \%\right)$. The data from the subgroup analysis of treatment history, the presence or absence of cirrhosis, and duration of treatment are presented in Table 3.

\section{Relapse Rates in the SL and SLR Groups}

Next, the relapse rates were compared in patients that received the triple and dual therapy. Data revealed that the relapse rates were comparable between groups $(\mathrm{RR}=0.746, \quad 95 \% \quad \mathrm{CI}=0.441, \quad 1.261, \quad P=0.274$, $I^{2}=30.6 \%$; Fig. 3). 
Table 2 Assessment of the quality of the studies included in the meta-analysis

\begin{tabular}{|c|c|c|c|c|c|c|c|c|c|c|c|c|c|}
\hline \multirow[t]{2}{*}{ Author } & \multirow[t]{2}{*}{ Year } & \multicolumn{3}{|c|}{ Randomization } & \multicolumn{3}{|c|}{ Allocation concealment } & \multicolumn{3}{|c|}{ Blinding method } & \multicolumn{2}{|l|}{ Withdrawals } & \multirow[t]{2}{*}{ Total score } \\
\hline & & A & Un & In & A & Un & In & A & Un & In & Description & Undescribed & \\
\hline Eric et al. [24] & 2014 & Yes & & & Yes & & & Yes & & & Yes & & 7 \\
\hline Edward et al. [25] & 2014 & Yes & & & Yes & & & Yes & & & Yes & & 7 \\
\hline Kris et al. [26] & 2014 & & Yes & & Yes & & & Yes & & & & Yes & 5 \\
\hline Nezam et al. [27] & 2014 & & Yes & & Yes & & & Yes & & & & Yes & 5 \\
\hline Nezam et al. [28] & 2014 & & Yes & & Yes & & & Yes & & & Yes & & 6 \\
\hline Marc et al. [29] & 2015 & Yes & & & Yes & & & Yes & & & Yes & & 7 \\
\hline Masashi et al. [30] & 2015 & Yes & & & Yes & & & Yes & & & Yes & & 7 \\
\hline
\end{tabular}

In the randomization, allocation concealment and blinding method, if the method adequate $=2$ scores, unclear $=1$ score and inadequate $=0$ score

$A$ adequate, $U n$ unclear, $I n$ inadequate comparing the SVR12 rate between the SLR and SL groups
Fig. 2 Meta-analysis

Study

ID

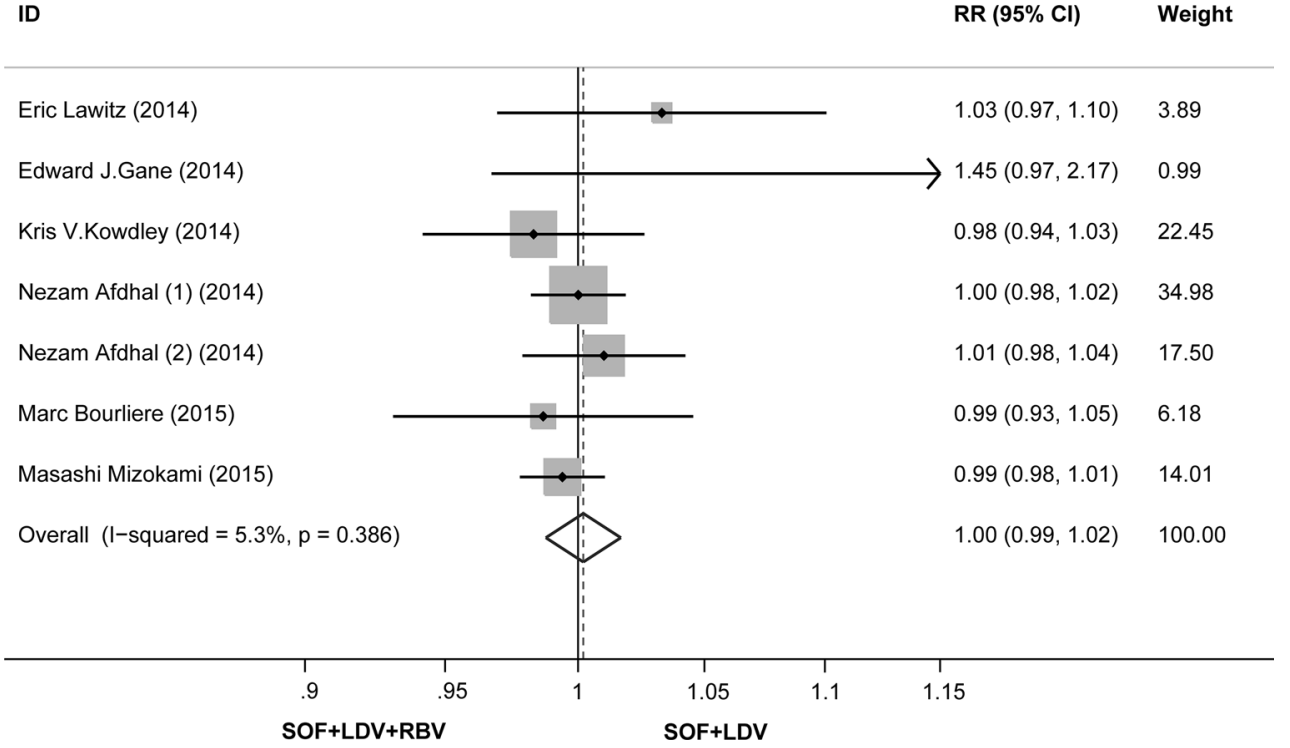

Table 3 Results of subgroup analyses evaluating the difference in SVR12 based on treatment history, the presence or absence of cirrhosis, and duration of treatment in patients with $\mathrm{HCV}$ genotype 1 infection

\begin{tabular}{|c|c|c|c|c|c|c|}
\hline \multirow[t]{2}{*}{ Subgroups } & \multirow[t]{2}{*}{ Number of study SLR/SL } & \multirow[t]{2}{*}{$\mathrm{RR}$} & \multirow[t]{2}{*}{$I^{2}(\%)$} & \multirow[t]{2}{*}{$P$ value } & \multicolumn{2}{|c|}{$95 \% \mathrm{CI}$} \\
\hline & & & & & Lower & Upper \\
\hline \multicolumn{7}{|l|}{ Treatment history } \\
\hline TN patients & $671 / 901$ & 0.994 & 0.00 & 0.567 & 0.975 & 1.014 \\
\hline PT patients & $338 / 325$ & 1.020 & 32.60 & 0.201 & 0.990 & 1.051 \\
\hline \multicolumn{7}{|c|}{ The presence or absence of cirrhosis } \\
\hline With cirrhosis & $868 / 868$ & 1.003 & 0.00 & 0.629 & 0.990 & 1.016 \\
\hline Cirrhosis only & $80 / 88$ & 1.022 & 70.90 & 0.528 & 0.955 & 1.094 \\
\hline \multicolumn{7}{|c|}{ Duration of treatment } \\
\hline 8 weeks & $237 / 451$ & 1.040 & 0.00 & 0.047 & 1.001 & 1.081 \\
\hline 12 weeks & $540 / 542$ & 1.010 & 59.00 & 0.374 & 0.989 & 1.031 \\
\hline 24 weeks & $328 / 326$ & 1.010 & 44.60 & 0.496 & 0.988 & 1.025 \\
\hline
\end{tabular}




\section{Treatment Safety in the SL and SLR Groups}

All of the included trials reported data regarding the incidence of AEs. Therefore, we conducted a meta-analysis to investigate the incidence of AEs and the rate of discontinuation due to AEs in patients receiving SLR versus SL therapy. The pooled data showed that there was an increased risk of AEs in the SLR group compared with the $\mathrm{SL}$ group $(\mathrm{RR}=1.140, \quad 95 \% \mathrm{CI}=1.095, \quad 1.187$, $P=0.000, I^{2}=0.0 \%$; Fig. 4). Overall, $2026(78 \%)$ of 2601 patients had at least one AE. The most common AEs were nausea, headache, insomnia, fatigue, and anemia. The addition of RBV to SL increased the incidence of drugrelated AEs, as shown in Table 4. We next analyzed the rate of treatment discontinuation due to AEs. Surprisingly, there was no difference in the rate of therapy discontinuation due to AEs between groups $(\mathrm{RR}=1.670,95 \%$ $\mathrm{CI}=0.666,4.185, P=0.274, I^{2}=0.0 \%$; Fig. 5).

\section{Publication Bias}

Finally, we investigated the risk of publication bias in the seven RCTs for the purpose of assessing the strength of the evidence. A funnel plot of the standard error log RR rate versus the RR rate was relatively symmetrical. No publication bias was identified (Fig. 6).

\section{Discussion}

The present study is the first attempt to review the literature and provide a comprehensive comparison of the efficacy and safety of the SL and SLR regimens for the treatment of patients with HCV genotype 1 infections. The results demonstrated that SVR12 and the relapse rate did not differ significantly between the two regimens. However, the incidence of AEs, including anemia, fatigue, headache, and nausea, was higher in patients that received the triple regimen compared with the dual regimen.

For over 20 years, the standard of treatment for $\mathrm{HCV}$ infections, including chronic HCV genotype 1 infection, has been the combination of PEG-IFN- $\alpha$ and RBV. This traditional therapy results in a suboptimal rate of sustained virological response (SVR) and an unfavorable AE profile [31]. Patients with HCV genotype 1 infection experience an even poorer outcome [32]. Although IFN-free regimens consisting of combinations of newly approved DAAs recently became available [33, 34], RBV continues to be included in a number of therapeutic regimens [24-30]. The current analysis suggests that the addition of RBV to the SL regimen cannot improve the rate of SVR12, regardless of the treatment history (treatment naive vs. treated previously). As for the duration of treatment, rates of SVR12 were similar in patients receiving 12 or 24 weeks of treatment between SLR and SL groups. However, the addition of RBV to the 8 weeks of SL regimen offered additional benefit to the rate of SVR12. It seemed like that the inclusion of ribavirin in the 8-week SL regimen with better efficacy than 8-week SL regimen alone appeared to be a more rational treatment option. With extension of the duration to 12 or 24 weeks, no additional benefit was associated with the inclusion of RBV in the SL regimen. The 12-week or 24-week SL regimen alone may have enough potential to cure most patients with $\mathrm{HCV}$ genotype 1 infection. Patients with cirrhosis resulting from chronic $\mathrm{HCV}$ infection are at risk of life-threatening complications,
Fig. 3 Meta-analysis comparing the relapse rate between the SLR and SL groups

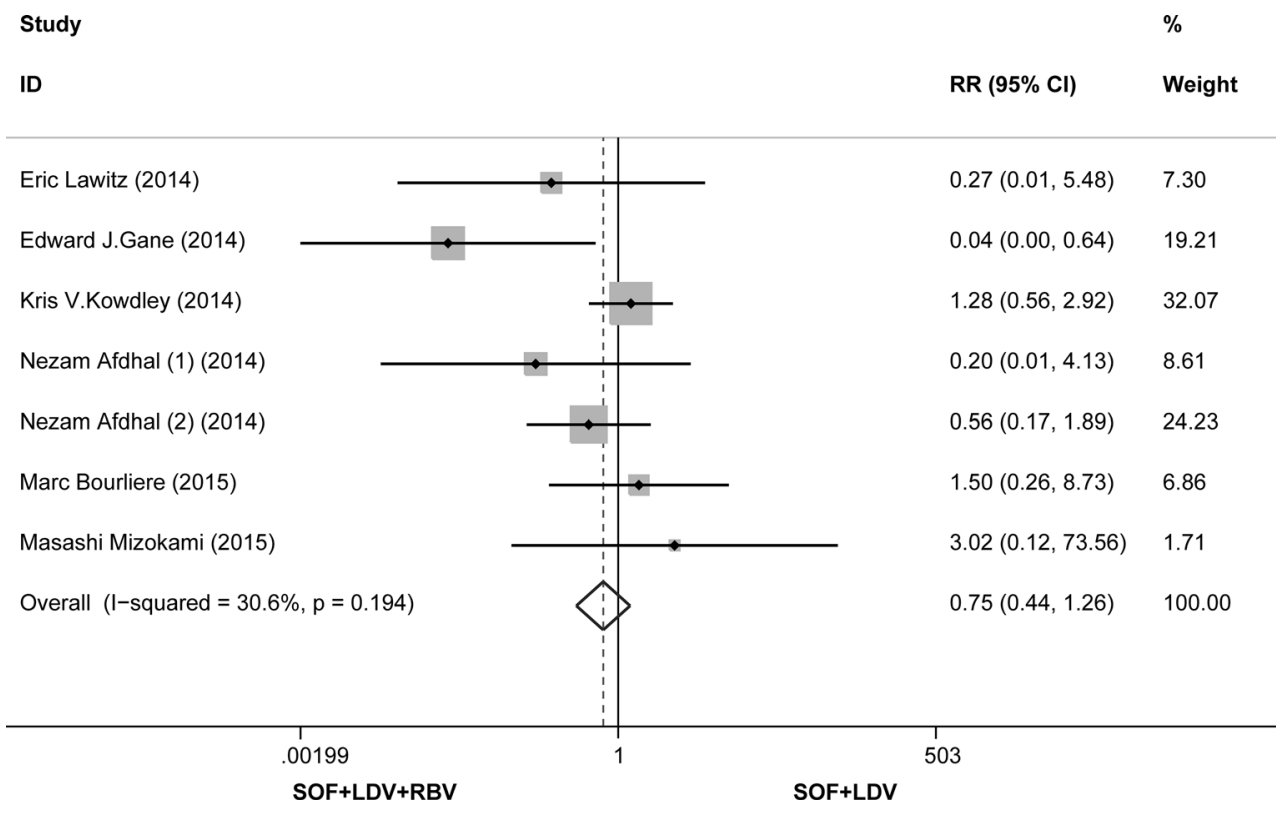



comparing the drug safety of the SLR and SL groups
Fig. 4 Meta-analysis

Study

ID

Eric Lawitz (2014)

Edward J. Gane (2014)

Kris V. Kowdley (2014)

Nezam Afdhal (2014)

Nezam Afdhal (2014)

Marc Bourliere (2015)

Masashi Mizokami (2015)

Overall (I-squared $=0.0 \%, p=0.662)$

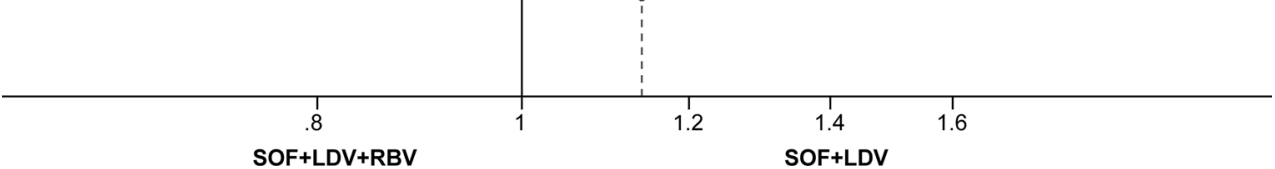

Table 4 Results of subgroup analyses evaluating the rate of AEs in patients with $\mathrm{HCV}$ genotype 1 infection between SLR and SL groups

Fig. 5 Meta-analysis comparing the treatment discontinuation rate due to AEs in the SL and SLR groups

\begin{tabular}{llrrrrr}
\hline AEs & Number of study & RR & $I^{2}(\%)$ & $P$ value & \multicolumn{2}{l}{$95 \%$ CI } \\
\cline { 5 - 7 } & SLR/SL & & & & Lower & Upper \\
\hline Nausea & $194 / 128$ & 1.725 & 0.0 & 0.000 & 1.395 & 2.132 \\
Insomnia & $181 / 96$ & 2.075 & 0.0 & 0.000 & 1.639 & 2.627 \\
Anemia & $108 / 8$ & 15.244 & 4.2 & 0.000 & 7.530 & 30.859 \\
Headache & $288 / 272$ & 1.162 & 49.6 & 0.043 & 1.005 & 1.343 \\
Fatigue & $352 / 256$ & 1.623 & 60.0 & 0.000 & 1.411 & 1.866 \\
\hline
\end{tabular}

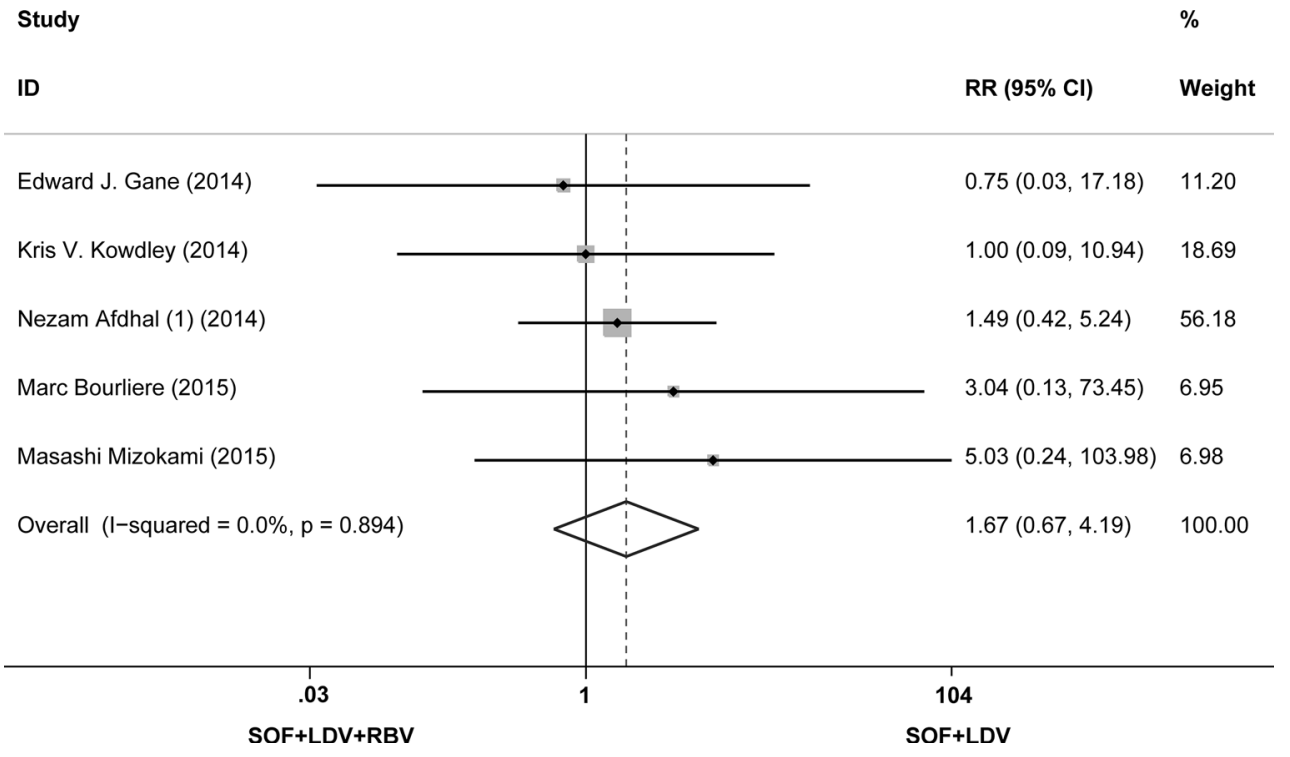

but consistently achieve lower SVR than patients without cirrhosis. SL plus ribavirin for 12 weeks and SL for 24 weeks provided similarly high SVR12 rates in previous non-responders with $\mathrm{HCV}$ genotype 1 and compensated cirrhosis [29]. Surprisingly, our stratified analyses based on the presence or absence of cirrhosis demonstrated that addition of RBV to the SL regimen did not improve the rate of SVR12 in patients including those with cirrhosis and 


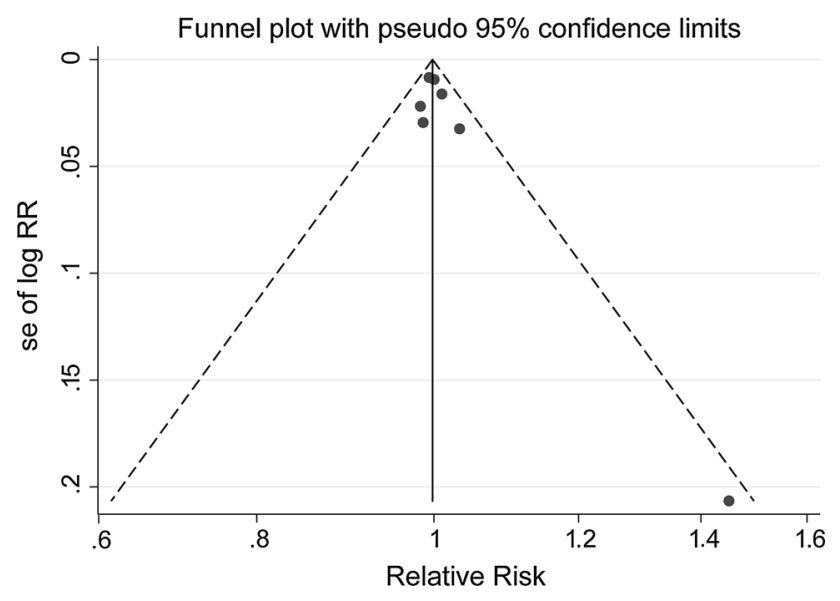

Fig. 6 Funnel plot for the seven studies included in the primary analysis

cirrhotic patients only. Among the included studies, only one study analyzed the SVR12 in patients without cirrhosis. There was no significant difference in patients without cirrhosis achieving SVR12 between SLR and SL groups [26]. Further high-quality studies which enrolled patients without cirrhosis are still needed to confirm these results.

The relapse rate was also comparable between treatment groups. Therefore, the current meta-analysis provides evidence that addition of RBV does not improve the efficacy of the SL regimen for the treatment of patients with genotype 1 infection. Furthermore, it was reported previously that the addition of RBV to SL therapy for 12 weeks or prolonging the treatment for 24 weeks could improve the SVR12 rate in patients with decompensated cirrhosis [35]. In contrast, another study reported that there was no significant difference in the SVR12 rate after 12 and 24 weeks of treatment with the SL regimen in treatment-naive genotype 1 patients, $16 \%$ of whom were cirrhotic [27]. As the amount of literature in this area increases, we will comprehensively evaluate whether prolonging the treatment period using the SL regimen could improve treatment efficacy in patients with HCV genotype 1 infection, particularly in patients that did not achieve SVR after treatment with PEG-IFN and $\mathrm{RBV}$, and with or without a protease inhibitor.

The available safety profiles of RBV are based primarily on the co-administration of RBV with IFN in the treatment of HCV infection and previous RBV monotherapy [36, 37]. The current meta-analysis demonstrated that there was a much higher risk of AEs (anemia, fatigue, headache, and nausea) with the SLR regimen compared with the SL regimen. Therefore, the 12-week or 24-week SL regimen with a lower risk of AEs and similar SVR12 rate compared to SLR regimen seemed to be a suitable therapy. Furthermore, this provides a unique opportunity to compare the safety of an RBV-containing and an RBV-sparing regimen in the absence of IFN. Interestingly, there was no difference in the incidence of discontinuation due to AEs between treatment regimens. We speculate that although the addition of RBV to the SL regimen increases the incidence of AEs, these tolerable side effects did not result in a higher rate of discontinuation.

The introduction DAAs, including the SL regimen, was an extraordinary development in the treatment of patients with $\mathrm{HCV}$. However, the very high cost of DAAs (cost per course: SOF, $\$ 84,000$; SOF plus LDV, $\$ 94,500$ ) is always challenging. Therefore, IFN-based therapies remain the preferred standard treatment option for $\mathrm{HCV}$-infected patients, particularly those living in low- and middle-income countries or those paying for treatment out-of-pocket [38]. The addition of RBV to the SL regimen will further increase the financial burden and potential AEs. Thus, the SL regimen is more reasonable for the treatment of patients with HCV. The current preferred IFN-based therapy remains a suitable treatment option for $\mathrm{HCV}$-infected patients and particularly for those with favorable IFN-response characteristics such as the IL28B genotype [39].

The current study has some limitations that must be acknowledged. First, most of the studies included in the analysis enrolled only non-cirrhotic patients. Thus, the results of our analysis may not be applicable to all patients with HCV genotype 1, particularly those with HCV-related cirrhosis. Second, some studies included interventions with a range of treatment doses. Unfortunately, we were unable to perform subgroup analyses according to the drug doses because of the small number of relevant studies identified. Furthermore, we could not accurately evaluate treatment efficacy, especially safety, of each regimen due to the lack of placebo controls.

In conclusion, the SLR regimen for 12 or 24 weeks had a similar efficacy as the SL regimen for the treatment of patients with HCV genotype 1. Although the 8-week SLR regimen showed superior SVR12 to the 8-week SL regimen, the addition of RBV to the SL regimen increased the risk of AEs, as well as the economic burden. Therefore, the 12-week or 24-week SL regimen should be recommended as the first-line treatment for patients with HCV genotype 1 infection, regardless of their prior treatment history and the presence or absence of cirrhosis.

Acknowledgments This research was supported by the National Natural Science Foundation of China (CN) (X2138, 81171560, 30930082, 81171561, 30972584); the National Science and Technology Major Project of China (2008ZX10002-006, 2012ZX1002007001, 2011ZX09302005, 2012ZX09303001-001, 2012ZX10002003); the National High Technology Research and Development Program of China (2011AA020111), the Key Project of Chongqing Science and Technology Commission (cstc2012ggyyjsB10007); the Chongqing Natural Science Foundation (cstc2011jjA10025); and the Medical Research Fund by Chongqing Municipal Health Bureau (2009-1-71); the Program for Innovative Research Team of Chongqing Kuanren Hospital. 


\section{Compliance with ethical standards}

Conflict of interest The authors declare that they have no conflict of interest.

Open Access This article is distributed under the terms of the Creative Commons Attribution-NonCommercial 4.0 International License (http://creativecommons.org/licenses/by-nc/4.0/), which permits any noncommercial use, distribution, and reproduction in any medium, provided you give appropriate credit to the original author(s) and the source, provide a link to the Creative Commons license, and indicate if changes were made.

\section{References}

1. Messina JP, Humphreys I, Flaxman A, et al. Global distribution and prevalence of hepatitis C virus genotypes. Hepatology. 2015;61:77-87.

2. Maasoumy B, Wedemeyer H. Natural history of acute and chronic hepatitis C. Best Pract Res Clin Gastroenterol. 2012;26:401-412.

3. Wray CM, Davis AM. Screening for hepatitis C. JAMA. 2015;313:1855-1856.

4. Dhanasekaran R, Sanchez W, Mounajjed T, Wiesner RH, Watt $\mathrm{KD}$, Charlton MR. Impact of fibrosis progression on clinical outcome in patients treated for post-transplant hepatitis $\mathrm{C}$ recurrence. Liver Int. 2015;35:2433-2441.

5. Williams IT, Bell BP, Kuhnert W, Alter MJ. Incidence and transmission patterns of acute hepatitis $\mathrm{C}$ in the United States, 1982-2006. Arch Internal Med. 2011;171:242-248.

6. Holmes JA, Thompson AJ. Interferon-free combination therapies for the treatment of hepatitis C: current insights. Hepatic Med Evid Res. 2015;7:51-70.

7. Swadling L, Klenerman P, Barnes E. Ever closer to a prophylactic vaccine for HCV. Expert Opin Biol Therapy. 2013;13:1109-1124.

8. EASL. EASL Clinical Practice Guidelines: management of hepatitis C virus infection. J Hepatol. 2014;60:392-420.

9. Heim MH. 25 years of interferon-based treatment of chronic hepatitis C: an epoch coming to an end. Nat Rev Immunol. 2013;13:535-542.

10. Sulkowski MS, Cooper C, Hunyady B, et al. Management of adverse effects of Peg-IFN and ribavirin therapy for hepatitis C. Nat Rev Gastroenterol Hepatol. 2011;8:212-223.

11. Calvaruso V, Mazza M, Almasio PL. Pegylated-interferon-alpha(2a) in clinical practice: how to manage patients suffering from side effects. Expert Opin Drug Saf. 2011;10:429-435.

12. Fried MW, Buti M, Dore GJ, et al. Once-daily simeprevir (TMC435) with pegylated interferon and ribavirin in treatmentnaive genotype 1 hepatitis C: the randomized PILLAR study. Hepatology. 2013;58:1918-1929.

13. Sulkowski MS, Asselah T, Lalezari J, et al. Faldaprevir combined with pegylated interferon alfa-2a and ribavirin in treatment-naive patients with chronic genotype $1 \mathrm{HCV}$ : SILEN-C1 trial. Hepatology. 2013;57:2143-2154.

14. Lawitz E, Lalezari JP, Hassanein T, et al. Sofosbuvir in combination with peginterferon alfa-2a and ribavirin for non-cirrhotic, treatment-naive patients with genotypes 1,2 , and 3 hepatitis $\mathrm{C}$ infection: a randomised, double-blind, phase 2 trial. Lancet Infect Dis. 2013;13:401-408.

15. Jacobson IM, McHutchison JG, Dusheiko G, et al. Telaprevir for previously untreated chronic hepatitis $\mathrm{C}$ virus infection. New Engl J Med. 2011;364:2405-2416.
16. Gower E, Estes C, Blach S, Razavi-Shearer K, Razavi H. Global epidemiology and genotype distribution of the hepatitis $\mathrm{C}$ virus infection. J Hepatol. 2014;61:S45-S57.

17. Infectious Diseases Society of America (IDSA) and American Association for the Study of Liver Diseases (AASLD). HCV Guidance: Recommendations for Testing, Managing, and Treating Hepatitis C. Available at: http://www.hcvguidelines.org/; 2016. Updated: 06.07.16. Changes made 08.07.16.

18. Petersen T, Townsend K, Gordon LA, et al. High adherence to all-oral directly acting antiviral $\mathrm{HCV}$ therapy among an inner-city patient population in a phase $2 \mathrm{a}$ study. Hepatol Int. 2016;10:310-319.

19. Manns M, Samuel D, Gane EJ, et al. Ledipasvir and sofosbuvir plus ribavirin in patients with genotype 1 or 4 hepatitis $\mathrm{C}$ virus infection and advanced liver disease: a multicentre, open-label, randomised, phase 2 trial. Lancet Infect Dis. 2016;16:685-697.

20. Ledipasvir + sofosbuvir (Harvoni). A therapeutic advance in genotype 1 hepatitis $\mathrm{C}$ virus infection, despite uncertainties. Prescrire Int. 2015;24:285-289.

21. Charlton M, Everson GT, Flamm SL, et al. Ledipasvir and sofosbuvir plus ribavirin for treatment of $\mathrm{HCV}$ infection in patients with advanced liver disease. Gastroenterology. 2015;149:649-659.

22. Parent N, Hanley JA. Assessing quality of reports on randomized clinical trials in nursing journals. Can $J$ Cardiovasc Nurs. 2009;19:25-39.

23. Ioannidis JP. Interpretation of tests of heterogeneity and bias in meta-analysis. J Eval Clin Pract. 2008;14:951-957.

24. Lawitz E, Poordad FF, Pang PS, et al. Sofosbuvir and ledipasvir fixed-dose combination with and without ribavirin in treatmentnaive and previously treated patients with genotype 1 hepatitis $\mathrm{C}$ virus infection (LONESTAR): an open-label, randomised, phase 2 trial. Lancet (London, England). 2014;383:515-523.

25. Gane EJ, Stedman CA, Hyland RH, et al. Efficacy of nucleotide polymerase inhibitor sofosbuvir plus the NS5A inhibitor ledipasvir or the NS5B non-nucleoside inhibitor GS9669 against HCV genotype 1 infection. Gastroenterology. 2014;146:e731.

26. Kowdley KV, Gordon SC, Reddy KR, et al. Ledipasvir and sofosbuvir for 8 or 12 weeks for chronic HCV without cirrhosis. New Engl J Med. 2014;370:1879-1888.

27. Afdhal N, Zeuzem S, Kwo P, et al. Ledipasvir and sofosbuvir for untreated HCV genotype 1 infection. New Engl J Med. 2014;370:1889-1898.

28. Afdhal N, Reddy KR, Nelson DR, et al. Ledipasvir and sofosbuvir for previously treated HCV genotype 1 infection. New Engl J Med. 2014;370:1483-1493.

29. Bourliere M, Bronowicki JP, de Ledinghen V, et al. Ledipasvirsofosbuvir with or without ribavirin to treat patients with $\mathrm{HCV}$ genotype 1 infection and cirrhosis non-responsive to previous protease-inhibitor therapy: a randomised, double-blind, phase 2 trial (SIRIUS). Lancet Infect Dis. 2015;15:397-404.

30. Mizokami M, Yokosuka O, Takehara T, et al. Ledipasvir and sofosbuvir fixed-dose combination with and without ribavirin for 12 weeks in treatment-naive and previously treated Japanese patients with genotype 1 hepatitis C: an open-label, randomised, phase 3 trial. Lancet Infect Dis. 2015;15:645-653.

31. Gogela NA, Lin MV, Wisocky JL, Chung RT. Enhancing our understanding of current therapies for hepatitis $\mathrm{C}$ virus (HCV). Curr HIV/AIDS Rep. 2015;12:68-78.

32. Alexopoulou A, Karayiannis P. Interferon-based combination treatment for chronic hepatitis $\mathrm{C}$ in the era of direct acting antivirals. Ann Gastroenterol. 2015;28:55-65.

33. Zhang X. Direct anti-HCV agents. Acta Pharm Sin B. 2016;6:26-31. 
34. Gonzalez-Grande R, Jimenez-Perez M, Gonzalez Arjona C, Mostazo Torres J. New approaches in the treatment of hepatitis C. World J Gastroenterol. 2016;22:1421-1432.

35. Di Bisceglie AM, Conjeevaram HS, Fried MW, et al. Ribavirin as therapy for chronic hepatitis C. A randomized, double-blind, placebo-controlled trial. Ann Internal Med. 1995;123:897-903.

36. Tassopoulos NC, Ketikoglou I, Tsantoulas D, et al. A randomized trial to assess the efficacy of interferon-alpha daily in combination with ribavirin in the treatment of naive patients with chronic hepatitis C. J Viral Hepatitis. 2003;10:383-389.

37. Martin NK, Vickerman P, Brew IF, et al. Is increased hepatitis C virus case-finding combined with current or 8-week to 12-week direct-acting antiviral therapy cost-effective in UK prisons? A prevention benefit analysis. Hepatology. 2016;63:1796-1808.

38. Stattermayer AF, Ferenci P. Effect of IL28B genotype on hepatitis B and C virus infection. Curr Opin Virol. 2015;14:50-55.

39. Gentile I, Borgia G. Ledipasvir/Sofosbuvir administration achieves very high rate of viral clearance in patients with $\mathrm{HCV}$ genotype 1 infection without cirrhosis, regardless of ribavirin coadministration or length of treatment. Evid Based Med. 2014;19:223-224. 